\title{
Commentary \\ Social learning in horses from a novel perspective
}

Konstanze Krueger, Birgit Flauger

University of Regensburg Department of Biology I

corresponding author: Konstanze Krueger: konstanze-krueger@equine-science.de

'The original publication is available at http://dx.doi.org/10.1016/j.beproc.2006.08.010

Social learning in horses from a novel perspective Behav. Process. 76 (1) 37-39

Horses have been domesticated in between 2.500 and 5.000 (Clutton-Brock, 1981) years ago, ever since humans tried to train them for fast and correct responses to special tasks. In this sense it appears to be important to gain more insight in equine learning abilities. Murphy and Arkins (2006) succeeded to write a comprehensive and very useful review on equine learning behaviour. Animal learning theories in general used to focus on explaining the mechanisms for individual learning and only for the last two decades social aspects and cognitive abilities of animals have been incorporated into learning research. It is not surprising that most equine learning research concentrates on the mechanisms of individual learning as well, although it is kind of obscure that there is very little knowledge about horses social learning and their cognitive abilities (Nicol, 2002; Murphy \& Arkins, 2006), since horses have been companions to humans for such a long time. May be this can be explained by the fact that it is still under discussion whether animal learning theory is applicable to social learning, or whether different mechanisms are responsible for social and asocial learning (Heyes, 1994; Nicol, 1996).

Murphy and Arkins (2006) as well as Nicol (2002) discussed several studies (Baer et al., 1983; Baker \& Crawford, 1986; Clarke et al., 1996; Lindberg et al., 1999) which have been designed in the effort to evaluate horses' social learning abilities, which those manuscripts actually had difficulties to prove. These tests and more recent approaches to the subject all used a modified but more or less the same methodology (McLean, 2004b).

Nevertheless, the tests of Lindberg et al. (1999) differ fundamentally from those of Baer et al. (1983), Baker \& Crawford (1986) and Clarke et al. (1996). The latter tested for a discrimination task between two defined food-buckets, whereas Lindberg et al. (1999) set out to test a goal directed imitation of operating a test apparatus. Therefore I will not proceed to discuss Lindbergs research any further.
In the research of Baer et al. (1983), Baker \& Crawford (1986) and Clarke et al. (1996) food was baited in one of two differential coloured buckets of a learning apparatus from which a demonstrator was trained to discriminate between two buckets. An observer horse watched the demonstrator while persistently feeding only from a bucket of an identical colour, which was randomly placed either on the left or on the right side of the test apparatus. Even thought, none of the authors believed in having proved social learning in horses a closer analysis of the discrepancies between their experimental set-up and the outcome of their research hint to some alternative explanations.

Baer et al. (1983) found no signs of observational learning in their test series, because observers showed only slightly less errors than the control group. Still the data of the first day, which are most interesting in terms of evaluating observational learning effects, were eliminated from the analyses since the author felt that they were affected to extraneous stimuli. A response to the observation of the previous discrimination by the demonstrator was first tested after 24 hours.

Baker and Crawford (1986) concluded from the outcome of their tests, that horses might "avoid" the feeding territory of strangers, the demonstrator, even thought the demonstrator was removed before the observer was tested ( $p$ value "avoidance" $=0.01$ ). On the first choice horses significantly went to the bucket from which the demonstrator did not feed before. They argued that horses may expect that there is no food in the bucket left, where the demonstrator fed. Still they could not prove observational learning because observers and control horses had similar numbers of correct first choices.

This could also be evaluated in Clarke et al. (1996) as well as the tendency of observer horses to "avoid" the bucket the demonstrator fed from ( $p$ value "avoidance" $=0.07$ ). In addition a strong significant effect of prior observation on latency to approach the goal 
area on the first trial could be shown. This suggests that horses learn "something" about the general location of food from the demonstrator's performance. Clarke et al. (1996) argued that local rather than stimulus enhancement mechanism underlie any effect of observational learning in horses and those horses might be attracted to the general location where they have observed other horses feeding, but not to the same spot.

All three experiments aimed in perceiving a goal directed response in terms of a "classical" imitation (Galef, 1988; Heyes, 1994). The mechanism underlying this imitation is clearly goal-directed. For a positive prove of social learning matching behaviour, behaviour like that of a demonstrator (Heyes, 1994), was expected. Matching behaviour is indeed the only widely recognized outcome of social learning. Little attention has been paid to the possibility that social learning may have a variety of effects in addition to the production by the learner, or observer, of behaviour resembling that of an observed animal, or demonstrator. But in the case of imitation, learning can also result from socially mediated exposure to a negative relationship involving an aversive stimulus (an avoidance contingency) and thus result in novel non-matching behaviour. Overshadowing by dominance related previous experiences and by procedural feeding experiences could as well influence the outcome of the tests (Heyes, 1994).

As to the argument of Clarke et al. (1996), that horses might rather be affected by local enhancement than by stimulus enhancement, it could be argued that both buckets showed the same cues. The same food was baited in both buckets, Clarke et al. (1996) made sure that both buckets were marked with the same olfactory cues from previous feeding of the demonstrator and the buckets randomly changed positions. This rather hints to a stimulus enhancement mechanism, even more since is usually defined with reference to matching behaviour (Heyes, 1994). But the fact, that horses change their response to the buckets over subsequent trials, and stimulus enhancements should be persistent over all trials, rather hint to the point that horses actually showed imitation, as it is common in social learning processes.

But what actually did they learn? Clarke et al. (1996) already argued that horses at least learned "something" and they acquired their knowledge socially. So, may be we could find a line by discussing social influences on the test horses and their previous feeding experiences.

Murphy and Arkins (2006) discussed that the familiarisation procedure might not have been sufficient for a social learning task. They kept telling that observational learning may be influenced by a dominance hierarchy, whereby subjects might have more interest in, or possibly be more motivated by, the action of a "respected" conspecific. To solve the problem, they proposed the importance of training a dominant type of animal for the demonstrator position. This, actually, is one of the weak spots of all three manuscripts since there is no hint in either manuscript which kind of dominance status the demonstrator holds.

In the following Murphy and Arkins (2006) propose that it might be important to consider the social background of the horses since research data demonstrate that socially reared and kept horses learn training tasks quicker than those housed in individual stalls (Rivera et al., 2002; Sondergaard \& Ladewig, 2004). In addition, it has been demonstrated that socially reared rats had a tendency to imitate the behaviour they had observed, but rats raised in isolation performed the opposite behaviour to that observed, indicating a failure to use a conspecific as a reference point in the task (Reed et al., 1996). In chimpanzees Hare et al. (2000) proved that subordinate chimpanzees only chose food which was hidden behind a small barrier in a manner that the dominant animal could not see it. They even highlighted in a subsequent publication (Hare et al., 2001) that chimpanzees seem to know which particular animal watched the important event, since subordinates went for food when the observing dominant animal was exchanged by a non-observing dominant animal.

Unfortunately no information how horses were raised or socialised is given in the papers, with the exception of Baer's et al. (1983) report that their horses were group fed. On the other hand there is no information about whether the demonstrator was still visible for the observer horse after being removed from the test apparatus or not.

While taking advantage of the specific "following behaviour" horses show towards humans in a riding arena, in a recent research series we investigated whether bystander horses adjust their response to an experimenter according to their own dominance relationship with the horse whose reaction to the experimenter they had observed before. We suggested, that horses immediately followed the experimenter after previously watching a dominant horse doing so, but did not follow after observing a subordinate horse or a horse from another social group doing so (Krueger \& Heinze, submitted). Additionally, in another test series (Krueger, unpublished data) in which we tried to find out whether horses would follow the gazes of their conspecifics horses paid more attention to dominant horses from their own social group than to subordinate horses or those belonging to other social groups. The social affiliation and the dominance hierarchy seemed to have major influence in the horses motivation to pay attention to the gazes of conspecifics. 
These informations urged us to start a control trial concerning social aspects of the test-series by Baer et al. (1983), Baker \& Crawford (1986) and Clarke et al. (1996). First preliminary data from this series (Krueger \& Flauger, in prep) confirm that horses do not dare to feed from the same spot than another conspecific, no matter whether subordinate or dominant, when the conspecific is still feeding. Also they prefer to choose the bucket from which the dominant animal did not feed before when the dominant animal is still present but tied to a pole. In contrast they are unconcerned whether a subordinate animal is still present but tied to a pole, because they tend to return to the same bucket no matter at which bucket the subordinate fed from before. Finally, they stayed with the system of returning to the same feeding spot than in previous trials when the dominant animal has been removed out of sight. This behaviour is consistent with the observation of Devenport und Patterson (2005). They declared that after short time intervals horses prefer to return to the same foraging spot unless the spot is cropped or they realise that feed at another spot is plentiful and in a better quality. We could argue, that in the case of Baker \& Crawford (1986) and Clarke et al. (1996) the decision of the horses to change their normal feeding habits might be influenced by strong mechanisms. Since they changed their behaviour af-

\section{References:}

Baer, K.L., Potter, G.D., Friend, T.H., Beaver, B.V., 1983. Observation effects on learning in horses.

Applied Animal Ethology 11, 123-129.

Baker, A.E.M., Crawford, B.H., 1986. Observational learning in horses. Applied Animal Behaviour Science 15, 7-13.

Clarke, J.V., Nicol, C.J., Jones, R., McGreevy, P.D., 1996. Effects of observational learning on food selection in horses. Appl. Anim. Behav. Sci. 50, 177184.

Clutton-Brock, J., 1981. Domesticated animals, from early times. London: Britisch Museum of Natural History.

Devenport, J.A. Patterson, M.R., Devenport, L.D., 2005. Dynamic averaging and foraging decisions in horses (Equus caballus). J. Comp. Psychol. 119, 352-358.

Galef , B.G., 1988. Imitation in animals: history, definition and interpretation of data from the psychological laboratory. In Zentall T.R. and Galef B.G. (Eds.), Social Learning: Psychological and Biological Perspectives. pp. 3-28. Erlbaum, Hillsdale, N. J..

Hare, B., Call, J., Agnetta, B., Tomasello, M., 2000. Chimpanzees know what conspecifics do and do not see. Animal Behaviour 59, 771-758.

Hare, B., Call, J., Tomasello, M., 2001. Do chimpanzees know what conspecifics know? Animal Behaviour 61, 139-151. ter observation they should have learned "something" through observational learning. Obviously social effects on horses learning abilities do not always result in matching behaviour.

From this point of view I totally agree with Murphy and Arkins (2006) that the social affiliation and the dominance hierarchy is important to evaluate the reaction of horses to social learning tests. Concerning the test series of Baer et al. (1983), Baker \& Crawford (1986) and Clarke et al. (1996) it would also be necessary to know whether the demonstrator was still visible to the observer horses and what kind of previous feeding experiences they were exposed to. Since horses constitute a highly social species much of their cognitive abilities might be connected to social experiences. By incorporating social aspects into learning trials it will be possible to gain insight into horses 'social learning abilities. It has also been documented that it is possible to improve horse training tremendously while paying tribute to the horses highly developed social behaviour (Rivera et al., 2002; Sigheri et al., 2003; Krueger, 2006). Horse training can be gentler to the horse, quicker and more effective by applying social training techniques. Nevertheless it should be taken into account that the effect of social learning could as well result in non-matching behaviour.

Heyes, C.M., 1994. Social learning in animals: categories and mechanisms. Biol.Rev. 69, 207-231.

Krueger, K., 2006. Behaviour of horses in the "Round pen technique". Appl. Anim. Behav. Sci. in press.

Murphy, J., Arkins, S., 2006. Equine Learning Behaviour. Behavioural Processes in press.

Nicol, C.J., 1996. Farm animal cognition. Journal of Animal Sience 62, 375-391.

Nicol, C J., 2002. Equine learning: progress and suggestions for future research. Appl. Anim. Behav. Sci. 78, 193-208.

Reed, P., Skiera , F., Adams, L., Heyes, C.M., 1996. Effects of Isolation Rearing and Mirror Exposure on Social and Asocial Discrimination Performance. Learning and Motivation 27, 113-129.

Rivera, E., Benjamin, S., Nielsen, B., Shelle, J. \& Zanella, A. J. 2002. Behavioral and physiological responses of horses to initial training: the comparison between pastured versus stalled horses. Appl. Anim. Behav. Sci. 78, 235-252.

Sighieri, C., Tedeschi, D., de Andreis, C., Petri, L., Baragli, P., 2003. Behaviour patterns of horses can be used to establish a dominant-subordinate relationship between man and horse. Animal Wellfare 12, 705-708.

Sondergaard, E., Ladewig, J., 2004. Group housing exerts a positive effect on the behaviour of young horses during training. Appl. Anim. Behav. Sci. 87, 105-118. 